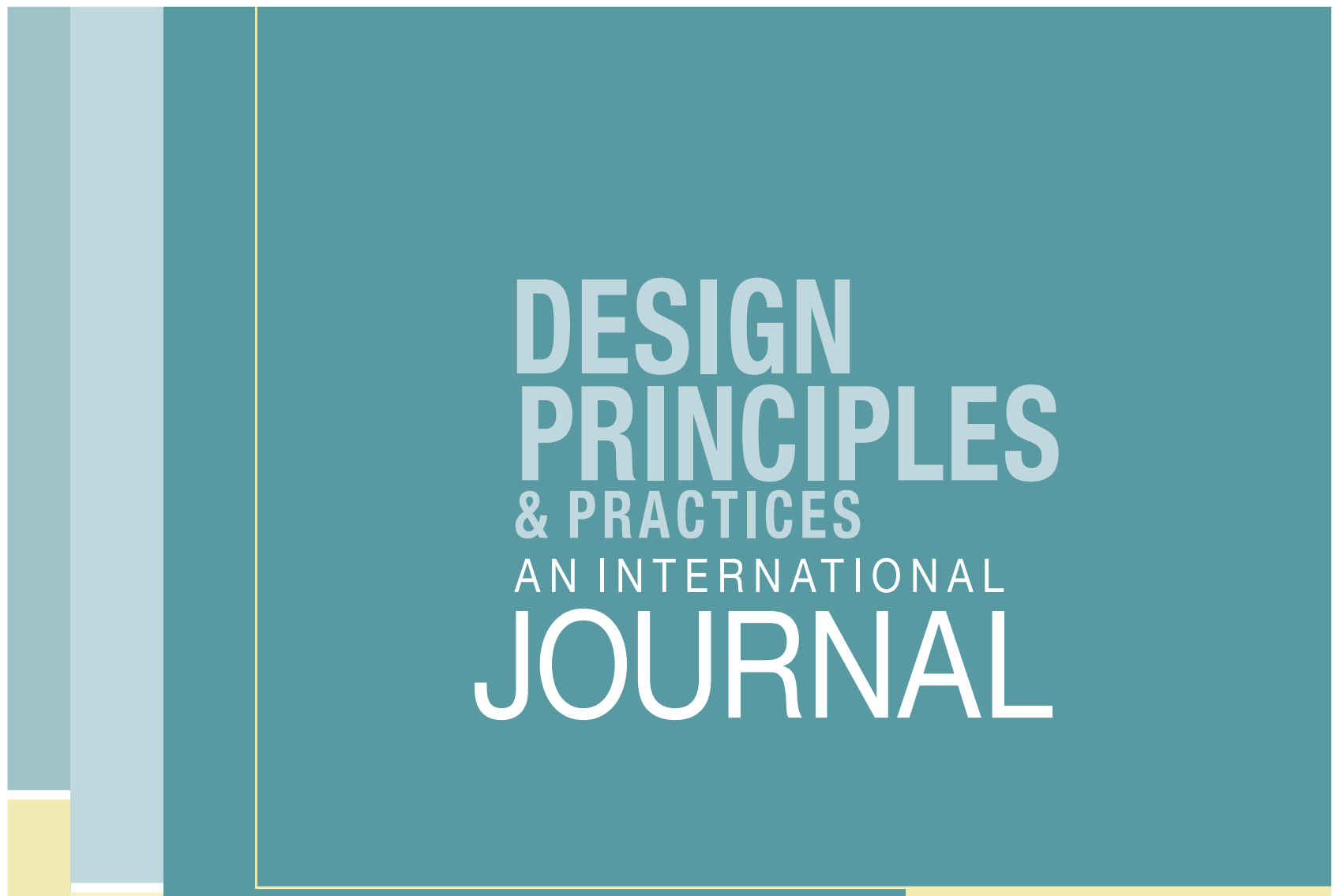

Volume 4, Number 6

The Mathematics of Domestic Modernism (19221934): An Analysis of Correlations Between Façade Complexity, Orientation, Address and Permeability

Michael J. Ostwald and Josephine Vaughan 
DESIGN PRINCIPLES AND PRACTICES: AN INTERNATIONAL JOURNAL http://www.Design-Journal.com

First published in 2011 in Champaign, Illinois, USA by Common Ground Publishing LLC www.CommonGroundPublishing.com.

(C) 2011 (individual papers), the author(s)

(C) 2011 (selection and editorial matter) Common Ground

Authors are responsible for the accuracy of citations, quotations, diagrams, tables and maps.

All rights reserved. Apart from fair use for the purposes of study, research, criticism or review as permitted under the Copyright Act (Australia), no part of this work may be reproduced without written permission from the publisher. For permissions and other inquiries, please contact

<cg-support@commongroundpublishing.com>.

ISSN: $1833-1874$

Publisher Site: http://www.Design-Journal.com

DESIGN PRINCIPLES AND PRACTICES: AN INTERNATIONAL JOURNAL is peerreviewed, supported by rigorous processes of criterion-referenced article ranking and qualitative commentary, ensuring that only intellectual work of the greatest substance and highest significance is published.

Typeset in Common Ground Markup Language using CGCreator multichannel typesetting system

http://www.commongroundpublishing.com/software/ 


\title{
The Mathematics of Domestic Modernism (1922-1934): An Analysis of Correlations Between Façade Complexity, Orientation, Address and Permeability
}

\author{
Michael J. Ostwald, The University of Newcastle, NSW, Australia \\ Josephine Vaughan, The University of Newcastle, NSW, Australia
}

\begin{abstract}
A common view in design scholarship is that the form or shape of a building is a reflection of the exigencies of its site, function and materiality. Thus, the façade of a house is shaped by its orientation or siting, the approach to the entry and the number and type of openings in the façade (being a reflection of the functional zones of the interior). Regardless of whether individual architects agree with this proposition or not, the relationship between form, function and site, remains a touchstone in architectural pedagogy and critique. However, despite a large number of qualitative examples in support of this proposition being available, there has never been a quantitative approach to measuring this relationship. In response to this situation, this paper proposes the adaptation of one of the few, well-supported approaches for the mathematical analysis of the visual properties of an architectural design; computational fractal analysis. Using ten Modernist houses as a case study set, the data produced by the computational analysis of these works is coded into three categories, orientation, approach and permeability. In this way it is possible to seek evidence of any correlation between the formal complexity of a façade and the impact of siting, access and program on that building. The purpose of this analysis is not to assess the performance of these architects' works, instead it is to propose one approach to testing the relationship between form and orientation, address and permeability.
\end{abstract}

Keywords: Computational Fractal Analysis, design assessment, domestic architecture

\section{Introduction}

$\mathrm{A}$

COMMON ASSUMPTION in architectural design is that the façade of a building is typically shaped by a combination of environmental, semiotic and functional conditions (Feininger 1956; Grillo 1975; Jones 1992; Frederick 2007; Box 2007; Ching 2007). These three characteristics are not necessarily all present in all architecture, but they are apparent in many buildings (Kruft 1994). Moore, Allen and Lyndon propose that this is particularly true in the case of domestic architecture where a façade is formed "in response to the resources, climate and topography of a particular region" (1974: 71). They maintain that a "house is in delicate balance with its surroundings" and that it "speaks" of or expresses something about its capacity to accommodate "human activities" and attitudes (1974: 49). In this way, the form of a house can be understood as a reflection of three factors; orientation or siting, address or approach and permeability (which is viewed as an expression of program).

The first of these three factors, orientation, is related to the impact of the environment on a design (Leatherbarrow 2000). Most houses are shaped to respond to the movement of the sun, either to restrict its impact or to capture its energy. The second factor is concerned with

Design Principles and Practices: An International Journal

Volume 4, Number 6, 2011, http://www.Design-Journal.com, ISSN 1833-1874 
the way in which a building addresses a visitor, or the way the building presents its public and private façades (Venturi 1966; King 2005). The design of a façade generally shifts to acknowledge points of entry and to signal rights of access. The final of the three factors anticipates that the function of a building shapes the number and type of openings in the building's façade. Collectively, these assumptions are all reliant on the belief that design is typically an adaptive and responsive process.

Despite the positioning of these assumptions as being normative in architecture, there have been no quantitative or mathematical analyses to support the efficacy of this position. One reason for this lack of detailed investigation is that there are relatively few mathematical techniques for the analysis of architectural form. The present paper proposes to begin the process of redressing this situation with the assistance of the computational method for determining the "approximate fractal dimension" or "characteristic visual complexity" of an architectural façade. This method produces a quantitative calculation of the formal complexity of every elevation of a building. It is then possible to code this data in accordance with the orientation of the façade (north, east, south, west), the address of the façade (front, left, back, right) and the number of openings in the façade. At the end of this process it should be possible to test if there is any pattern in the relationship between the visual complexity of a façade and its siting, address or internal program.

The focus of the testing is ten early Modern houses (1920-30s) by Le Corbusier and Eileen Gray. In total, five houses by each of the two architects are analysed, giving mathematical results for the visual complexity of 36 façades that are then coded into 108 data sets. The interpretation of the results for each of the two architects' works is informed not only by the mathematical results, but also by a reading of their design theory and stated method.

Following this introduction, the paper provides a brief description of the theory of computational fractal analysis before explaining how the data generated from this method may be coded to seek patterns in the way in which a design responds to additional factors. The proposed analytical method is then outlined as a series of stages and the limitations of the method are discussed along with some guidance on interpreting the results. Thereafter, the paper describes in turn, each architects' works and the results of the fractal analysis and the coding process. Finally the paper comments on the usefulness of the method and the degree to which it was able to produce results that conformed to expectations.

\section{Computational Fractal Analysis}

Fractal geometry may be used to describe irregular or complex lines, planes and volumes that exist between whole number integer dimensions. This implies that, instead of having a dimension, or $D$, of 1,2 , or 3 , fractals might have a $D$ of $1.51,1.93$ or 2.74 . This concept can be readily understood by considering a thought experiment. Imagine the top surface of a table. From a distance, it might appear to be a perfect two-dimensional surface $(D=2)$. But, if a person rubbed their hands across the surface they would feel that the surface has some texture and this implies that the table surface is more than two-dimensional. Yet, the surface is hardly three-dimensional either. Mandelbrot suggests that, in essence, if the feeling of texture is very subtle then the actual dimension of the table might be just slightly higher than $D=2$; perhaps $D=2.1$. However, if the surface was scarred and heavily marked with the grain of its underlying material, it might have a $D=2.3$ (Mandelbrot 1982). There are a range of methods for making a determination of the fractal dimension of an object and one 
of the most common, the box-counting approach, was adapted by Bovill $(1996 ; 1997)$ for the analysis of architecture. Bovill's work demonstrates that the fractal dimensions of line drawings of elevations of different buildings can be determined using the box-counting approach. This method is useful because it is one of only a small range of quantifiable approaches for the analysis of the visual properties of buildings.

Several variations of the box-counting approach exist (Li, Du and Sun, 2009). In its architectural variant, the technique commences with a drawing of an elevation of a building, typically a house. A large grid is then placed over the drawing and each square in the grid is checked to determine if any lines from the façade are present in the square. Those grid boxes that have some detail in them are recorded. Next, a grid of smaller scale is placed over the same façade and the same determination is made of whether detail is present in the boxes of the grid. A comparison is then constructed between the number of boxes with detail in the first grid and the number of boxes with detail in the second grid. This comparison is made by plotting a log-log diagram for each grid size (Bovill 1996). By repeating this process over multiple grids of different scales, an estimate of the fractal dimension of the façade is produced (see figure 1).
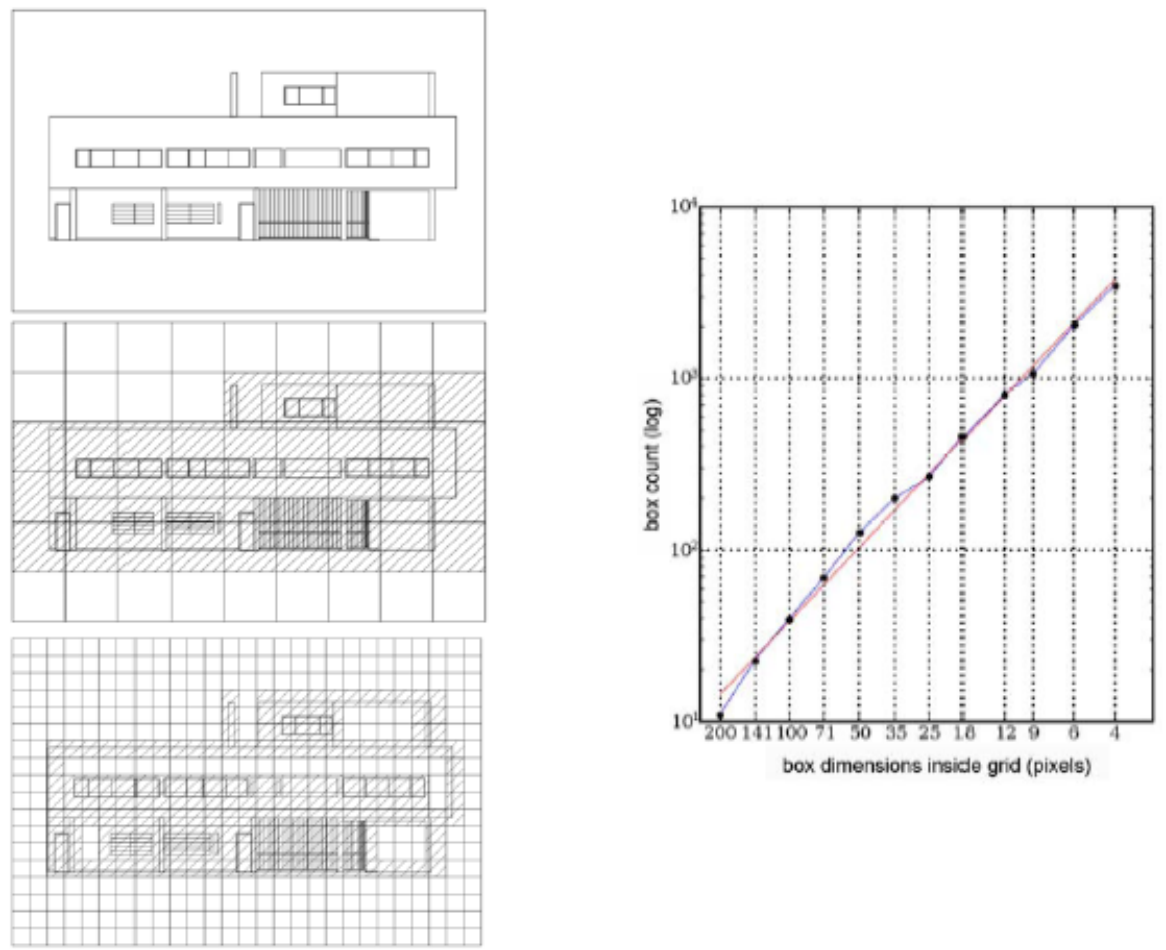

Figure 1: Example of the Box-counting Method Applied to an Elevation of Le Corbusier's Villa Savoye

In the last 15 years Bovill's method has been used to analyse vernacular architecture (Bechhoefer and Appleby 1997), urban and landscape design (Makhzoumi and Pungetti 1999) and ancient architecture (Burkle-Elizondo, Sala and Valdez-Cepeda 2004). Ostwald, 
Vaughan and Tucker (2008) developed a computational variation of this method which has since been applied to a wide range of designs by Frank Lloyd Wright, Peter Eisenman, Le Corbusier, Eileen Gray and Kazuyo Sejima (Ostwald and Vaughan 2008; 2009; Ostwald, Vaughan and Chalup 2009; Vaughan and Ostwald 2009).

There are several variations of the box-counting approach that respond to known deficiencies in the method. The four common variations are associated with balancing "white space" and "starting image" proportion, line width, scaling coefficient and moderating statistically divergent results. The solutions to these issues that have been proposed by Lorenz (2003), Foroutan-Pour, Dutilleul and Smith (1999) and Ostwald, Vaughan and Tucker (2008) are adopted in the present analysis. There are also several important observations to be made about the practical limitations of the method and its results.

In all cases, the method is concerned with the analysis of visible, external façades. Thus, the fractal analysis method is only concerned with what might be termed the "perimeter" or "boundary" façades of a building. That is, the formal expression of the building which is visible from points that are external to the structure and are largely perpendicular to the dominant geometry of the plan. Internal courtyard façades that are completely surrounded by built form are not part of this analysis. Some building forms are also sufficiently complex that small surfaces may not be visible on any elevation. For example, Alvar Aalto designed several domestic structures that have a "U-shaped" plan. For such houses, none of the four main elevations will show the full extent of the courtyard façades. Such circumstances do not undermine the application of this approach but they may limit its accuracy. A related limitation to the method concerns shared or party walls. Some houses might be rectilinear, but only the visible elevations can be usefully categorised. Thus, while this approach is most applicable to free-standing or detached houses, it can still be used for any visible façade but the greater the number of party walls the less likely the data has of being useful.

Finally, it should be noted that this method produces an approximate fractal dimension $(D)$ calculation for a two dimensional representation of a building façade. These may be combined together to produce a calculation of the typical visual complexity of a complete structure, but they are still only two-dimensional results. The development of a useful threedimensional variation of the box-counting approach is still in its early stages and to date no such method has been demonstrated in architecture.

\section{Data augmentation}

One of the practical challenges with applying the data developed from the computational fractal method is that it produces a single numerical result for each case being considered. This means that the data is in the form of isolated numbers on a linear scale and within a fixed range. This is akin to producing a chart which has a single " $\mathrm{x}$ axis" along which points are placed. The application of this type of data is essentially limited to comparisons between, for example, buildings that have higher levels of complexity and those that have lower levels. Or alternatively, this data can be used for comparisons between different architects' works or different periods in an architect's body of work. While such comparisons have been used to confirm a range of intuitive readings of architectural form, the potential of fractal analysis is limited unless the raw data produced in this way can be augmented with an additional dimension; in effect, producing a "y axis" to compliment the current, isolated, "x axis". This is why the coding of fractal data to record orientation, approach and permeability is so po- 
tentially interesting. First, it can be used to begin to quantitatively test a common assumption in architectural design (that form is responsive to a combination of siting and function) and second, it can demonstrate how fractal analysis techniques can be augmented in new ways. The three particular forms of augmentation covered in the present paper, orientation, address and permeability, are each described in detail in the following sections.

\section{Orientation}

This approach categorises the façades of a detached house by their orientation to the cardinal points of the compass (North, South, East and West). Not only is the differentiation of façades using this nomenclature common practice in architecture, but a determination of orientation, by way of magnetic bearings, is a universal system which can potentially be used for comparisons between most buildings. The primary exceptions would relate to geographic areas bounded by lines of latitude that approach the Arctic and Antarctic circles.

There are several practical considerations in making a determination of orientation. First, there are only four categories of orientation in the present work. While it might be possible to subdivide orientation by angle (within a $360^{\circ}$ array) very few architectural drawings record this information and it is not available for most of the projects being studied. This also means that when a façade does not have a clear direction (for example, it is facing North-NorthWest), the façade must be placed into the closest possible category (in this example, North). This data-augmentation approach is also most appropriate for dwellings that are both orthogonal and freestanding. This is because it assumes that a house may be described using a set of four elevations. If a house needs less than four elevations to describe it, then they are unlikely to be able to be classified into the four cardinal directions used here. For example, Frank Lloyd Wright designed several houses on an equilateral triangular grid and each of these houses only has, and needs, three elevations. Any attempt to force these three elevations into the four orientation categories produces problems for the accuracy and efficacy of the approach. A different situation occurs if the house has more than four major exterior surfaces or planes at different angles. For example, Wright also designed several houses that were based on a paired trapezoidal grid that produced hexagonal plans. In these circumstances it is generally possible to identify four cardinal elevations and usefully describe the dwelling in this way. However, for such houses some of the dominant planes or surfaces may appear in multiple views and may also never be seen from a perpendicular viewpoint. This situation doesn't prohibit the application of this approach but it may reduce the accuracy of the results.

\section{Address}

It is possible to code the fractal analysis data for each façade to reflect simple, experiential conditions. Whereas, the previous method sought to connect façade information to a universal system - magnetic bearings - the second approach is concerned with local and more intuitive determinations. While it might be imagined that houses designed for uniformly flat, rural sites would be strongly shaped by their orientation, for the majority of houses, the strategic siting options are much more limited and the impact of orientation tends to be ameliorated by the importance of addressing a street.

The majority of housing sites have a single obvious public face or "address" and a single private face. This means that the primary factor shaping the design of a typical façade is 
more likely to be related to the presentation of the house to the street, and the impact of positioning appropriate internal spaces to face the street, than to the passage of the sun. This implies that, perhaps more so than orientation, patterns should be discernable in the way in which dwellings orient their public and private façades.

The most common way of identifying the façades of a house revolves around the delineation between "front" and "back", with the former typically being the street address which most often also contains the formal entry to the house. Once the front is defined, most of the remainder of the façades are described in relation to the front. Thus, the façade that is facing in the opposite direction to the front becomes the back or rear façade. The remaining two façades, in a predominantly orthogonal or rectilinear plan, are the side façades. These also tend to be distinguished from each other by their relationship to the front. In particular, they are typically called the left or right side of the house, a relative determination made from a point perpendicular to the front facade.

There are several issues to consider in identifying the front façade. First, as noted above, the front is typically the location of the formal entry. Not all people will necessarily use this entry in a large house and in a more modern house the garage might partially replace this entry for everyday use. However, the majority of houses still have a formal entry for visitors and it is frequently signalled in some way by the positioning of a porch and by the siting of windows or paths. Moreover, the formal entry is normally, but again not always, sited in relation to the primary façade that addresses the street. There are some exceptions, including corner sites, but for the majority of houses the designation is relatively clear.

\section{Permeability}

An opening is typically a type of mediation between the interior and exterior environment of the house. At first glance, the concept of calculating the number of openings in a façade might seem irrelevant. However, the number of openings is a parameter that can easily be determined and it can have a subtle but important impact on multiple additional factors in the analytical process. For example, Moore, Allen and Lyndon argue that "[w]indows do more than let in light and air. The way they are placed in a wall affects our understanding of the whole house" (1974: 211). Moreover, "[w]indows can imply a great deal, both by the shape and their position" (1974: 211). For the purposes of the present paper, permeable "openings" include conventional doors and garage doors as well as windows. While this definition is adequate for the majority of houses, some architectural styles or approaches pose particular challenges to the approach. The following guidelines inform the process of counting openings.

First, as the analytical method is fundamentally concerned with design intent the focus of this approach is on counting major openings (being a void surrounded by solid) that penetrate a façade. This implies that the count is not to be dominated by the number of panels or panes within the window or door opening. This is because divisions within openings are often a function of the exigencies of materials and structural systems. For example, an opening in a façade is fitted with a single aluminium framed unit which has one sliding glass panel and one fixed glass panel; this is effectively one window. Conversely, a window in an arts and crafts style house that is made up of thirty or more diamond panes and associated lead moulding is still counted as just one window. The bigger problem with counting windows is associated with modern curtain-wall structures and expansive glass walls. For example, 
several of Le Corbusier's Modernist villas have extensive horizontal bands of glass in their façades that are only broken by the deliberate placements of vertical, steel mullions. At first this would seem to be a case of a single window, but if we look more closely the determination changes. For example, the mullions are not structural and they are not simply determined by the availability of glass in certain sizes. The mullions often correspond to a change in the interior function of the house. Under such circumstances, the opening will be classified as multiple.

\section{The Analytical Method}

Two sets of five houses were identified for analysis. Preference was given in each set for completed works, houses constructed within a relatively similar timeframe ( $<10$ years), and, within each set, a similar geographic region. There are some exceptions to this. First, several of Eileen Gray's houses are unbuilt and, in such cases, the design drawings were used instead of the working drawings as the basis for the analysis. Two of Le Corbusier's houses have party walls meaning that there are less than four elevations in each case. One of Gray's unbuilt works is also missing an elevation and it is impossible to reconstruct it from other views. Thus, 36 of the 37 possible elevations of these ten houses are analysed in this paper, not the 40 that might be anticipated.

Once the ten houses had been identified, the following stages occurred.

1. New drawings were prepared of each of the 36 elevations using consistent line weights, graphic styles and conventions. The majority of these drawings were traced from authorised reproductions of working drawings of the completed works.

2. The orientation of each façade was recorded either from the drawings or alternatively it was deduced by other means (including the use of Google earth and photographic observations). For two of the unbuilt houses by Gray orientation had to be assumed based on her standard graphic conventions and typical approach to locating functional areas.

3. The approach to each of the ten houses was identified from a review of plans, elevations, photographs and descriptions. Once this "front" façade was identified, the remainder of the façades were classified (back, left and right).

4. The number of permeable openings in each elevation was calculated and recorded. Once each of these four stages was completed, a variation of the standard fractal analysis method (Ostwald Tucker Vaughan 2008) was adopted.

5. The elevations of each individual house are separately grouped together and considered as a set.

6. Each elevation is analysed using Archimage and Benoit programs producing, respectively, a $D_{\text {(Archi) }}$ and a $D_{\text {(Benoit) }}$ outcome.

7. The $D_{\text {(Archi) }}$ and $D_{\text {(Benoit) }}$ results for each elevation are averaged together to produce a separate $D_{\text {(Elev) }}$ result.

8. Each $D_{(\text {Elev })}$ result is coded into one of four orientation categories $(\mathrm{N}, \mathrm{S}, \mathrm{E}, \mathrm{W})$, one of four approach categories (F, B, L, R) and has the number of openings recorded for it.

9. The coded data for each set of five houses are charted to seek patterns in the relationship between façade characteristic complexity and orientation, approach and permeability.

10. Steps 5-9 are repeated for each architect's works. 


\section{Interpretation of Results}

Before progressing to the analysis of the ten Modern houses, this section describes the logic underpinning the interpretation of the results. In the first instance, it explains why the fractal dimension is a useful indicator for the extent to which a design has been modelled in response to some external force. Secondly, it demonstrates the type of patterns that might be expected to be uncovered in this research if there was a clear correlation between façade complexity and the forces of orientation or approach. Finally, it considers the way in which the permeability calculation can be used as an indicator of the reliability of the fractal dimension for this particular purpose.

The fractal dimension of a façade is the product of any and all features which have an impact on the form, but not the materiality or texture, of a building. Thus, openings, rooflines, balconies, external steps, fixtures and facade modulation all have an impact on the fractal dimension. While the fractal dimension calculation does not differentiate between ornamental and functional forms, very few houses are completely dominated, from the perspective of built form, by ornamental or decorative features. Thus, in general, the fractal dimension of a façade could be considered a reflection of the degree to which a design has been shaped by some functional, programmatic or external forces. While this may be true for the majority of cases, highly modelled or sculptured buildings may produce less useful results using this method. Taking into account these limitations, and assuming that a clear correlation between façade complexity and orientation or approach exists, what type of results might be anticipated?

If an architect applies a consistent set of design values to similar scale projects in similar geographic regions over a relatively short timeframe it might be anticipated that a pattern could be uncovered in their work. For example, if all five houses by the same architect are on rural or "green-field" sites (without nearby neighbours) and within a similar geographic region (say southern France), then it might be anticipated that there would be some consistency between the complexity of a house's façade and its orientation. In this example, the southern façade would feature more windows and balconies to capture warmth and light, while the west façade would be relatively unadorned to shelter it from the afternoon sun and the cold winter winds. The northern and eastern façades would be between these two extremes. When charted, the results would, ideally, show a marginal rise from north to east and then a sharp rise to the southern elevation before a uniform fall to the lowest set of results for the west façades (see figure 2). 


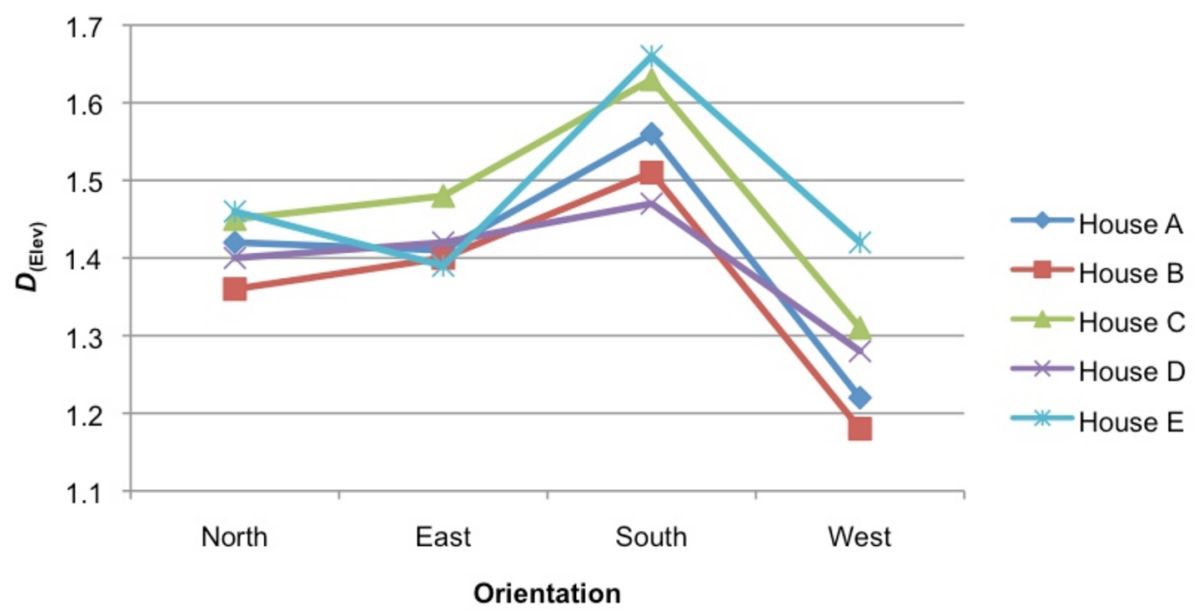

Figure 2: Results for a Hypothetical Set of Idealised Houses on Rural Sites in Southern France

For houses on urban or suburban sites it is unlikely that the "orientation" chart will contain such a pattern. Instead, all other things being equal, a pattern should be evident in the "approach" chart. For example, for buildings that face a busy urban street and have side façades facing neighbouring houses (typically in close proximity) and a single rear façade (to a private courtyard or garden) the following might be an expected pattern. The front façade has a middle level of relative visual complexity, reflecting the desire for natural light from the street, and the positioning of some formal areas (foyer, dining or home office) toward the busier side of the property. The left and right side façades would have little formal modelling, as they would have neither outlook nor need for shelter. The back or rear façade would have the highest level of visual complexity as it would contain the private spaces (bedrooms, living rooms) that require natural light and ventilation, along with any balcony spaces (see figure 3 ).

As previously noted in this section, it is possible that a highly sculptural built form may artificially increase the fractal dimension of a façade in such a way that it can no longer sustain the assumption that there is a relationship between façade complexity and external functional, environmental or programmatic forces. There is one way of determining if this situation has occurred. In a functional building a partial correlation between high $D$ values and a larger number of openings in a façade might be expected. This is because, the more openings there are in a façade, the more complexity it might be expected to have. An inverse correlation between number of openings and formal complexity is also informative. If the number of openings is high, and the complexity low, then the building must have little additional detail other than these openings. Conversely, if the number of openings is very low, and the $D$ value relatively high, then the façade must be heavily articulated, sculptured or modelled. 


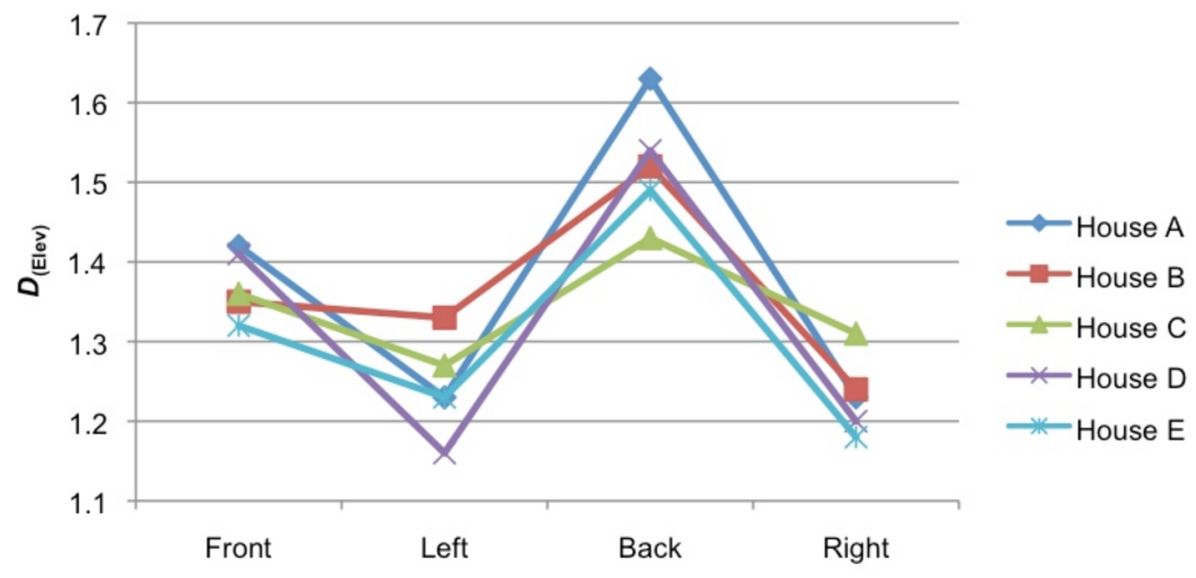

Address

Figure 3: Example, Hypothetical Set of Idealised Houses on Urban or Suburban Sites

\section{Le Corbusier: Results and Discussion}

The five houses by Le Corbusier that are analysed in the present research were completed between 1922 and 1928. Four of the five are in central France and the fifth in Germany. The houses are significant because during the 1920s Le Corbusier developed five strategies for an architecture that would reflect the technological and social advances of its era. Initially published in the journal L'Esprit Nouveau and later collated in Vers Une Architecture, these strategies (pilotis, plan libre, façade libre, fenêtre en longueur and toît jardin) are in their most refined form in the Villa Savoye. The first house, the Maison-atelier Ozenfant (1922-1923) in Paris, was designed as both a home and studio for the cubist painter Amédée Ozenfant. Set on a complex and steep corner site in a dense urban area, this three storey, white rendered masonry building has large glazing areas and a saw-tooth roof. The second house, the Villa Cook (1926) in Boulogne-sur-Seine, was described by Le Corbusier as a true cubic house because, as Gans observes, "[p]lan, section and elevation all derive from the same square and in reference to one another" $(2000,66)$. The house is a three-storey structure of white rendered masonry with a roof garden. The Villa Stein/de Monzie (19261928) also known as "Les Terrasses", is set on a narrow block in the suburbs of Vaucresson. The unusual domestic brief was for a house and studio for Gabrielle de Monzie and her daughter, to be shared with Michael and Sarah Stein. The origins of the fourth house may be traced to the late 1920s when Le Corbusier and Pierre Jeanneret were invited to produce residential designs for the Second International Exposition of the Deutscher Werkbund at Stuttgart. The resulting Weissenhof-Siedlung Villa 13 (1927) is on a corner block in the outskirts of the city. Le Corbusier and Jeanneret designed Villa 13 as a prototype for suburban row housing. The fifth house, the Villa Savoye (1928) or "Les heures Claires" is in Poissy, France. This famous two storey, freestanding house in white rendered masonry, with extensive roof garden, is set in an open landscape. 
The results for the computational fractal analysis of Le Corbusier's houses are recorded in Table 1. The analysis identified the least visually complex set of elevations, on average, as being those for the Weissenhof-Seidlung Villa 13 (with a range from $1.245<D_{\text {(Elev) }}<$ 1.5305 ) and the most complex as those for the Maison-atelier Ozenfant (with a range from $\left.1.4375<D_{\text {(Elev) }}<1.5405\right)$. The least complex elevation of the Villa Savoye was the west $\left(D_{\text {(Elev) }}=1.450\right)$ and the most complex was the south $\left(D_{\text {(Elev) }}=1.517\right)$. With both of these results being close, it confirms that the façades of the Villa Savoye all have a relatively similar level of visual complexity (figure 4).

Table 1: Results for Fractal Analysis of Each Façade for the Five Houses by Le Corbusier, coded by Orientation, Approach and Permeability

\begin{tabular}{|c|c|c|c|c|}
\hline House & $D_{\text {(Elev) }}$ & Orientation & Approach & Permeability \\
\hline \multirow[t]{3}{*}{ Maison/Atelier Ozenfant } & 1.515 & $\mathrm{~N}$ & $\mathrm{R}$ & 13 \\
\hline & 1.5405 & $\mathrm{E}$ & $\mathrm{F}$ & 10 \\
\hline & 1.4375 & S & $\mathrm{L}$ & 3 \\
\hline \multirow[t]{2}{*}{ Villa Cook } & 1.542 & $\mathrm{~N}$ & $\mathrm{~F}$ & 26 \\
\hline & 1.4395 & $S$ & B & 21 \\
\hline \multirow[t]{4}{*}{ Stein/De Monzie } & 1.5165 & $\mathrm{~N}$ & $\mathrm{~L}$ & 26 \\
\hline & 1.491 & $\mathrm{E}$ & $\mathrm{F}$ & 22 \\
\hline & 1.632 & S & B & 29 \\
\hline & 1.4275 & $\mathrm{~W}$ & $\mathrm{R}$ & 14 \\
\hline \multirow[t]{4}{*}{ Weissenhof-Seidlung } & 1.4835 & $\mathrm{~N}$ & B & 11 \\
\hline & 1.412 & $\mathrm{E}$ & $\mathrm{R}$ & 5 \\
\hline & 1.5305 & S & $\mathrm{F}$ & 13 \\
\hline & 1.2415 & W & $\mathrm{L}$ & 5 \\
\hline \multirow[t]{4}{*}{ Villa Savoye } & 1.512 & $\mathrm{~N}$ & $\mathrm{~F}$ & 27 \\
\hline & 1.4855 & $\mathrm{E}$ & $\mathrm{L}$ & 21 \\
\hline & 1.5175 & $\mathrm{~S}$ & B & 17 \\
\hline & 1.450 & W & $\mathrm{R}$ & 12 \\
\hline
\end{tabular}




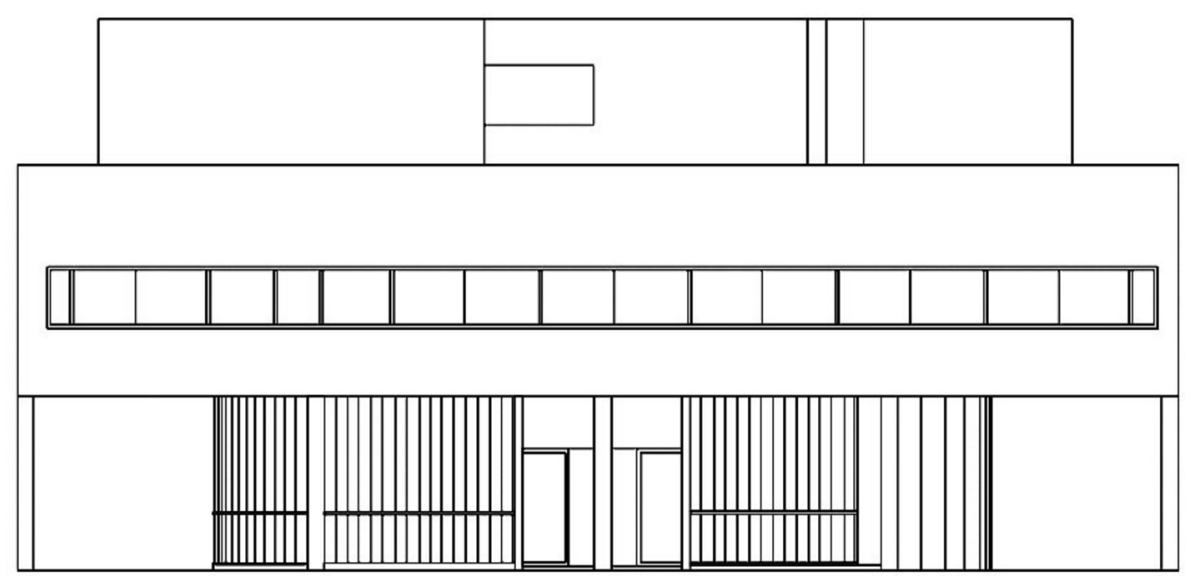

Figure 4: Le Corbusier's Villa Savoye. $D_{(\text {Elev })}=1.512$

The orientation chart for Le Corbusier's houses contains one visible trend (figure 5). For his relatively freestanding houses (the Villa Savoye, the Villa Stein and De Monzie, and the Weissenhof-Seidlung Villa 13) the southern elevation is the most complex façade and the western the least complex; this result mirrors the expected outcome outlined previously in the paper. The other two houses are more urban and have party walls explaining their lack of consistency. In contrast, the approach chart for Le Corbusier's houses does not display such a clear pattern although there is a tendency for back façades to be more visually complex than left or right façades, which is also broadly as anticipated in the method section (figure 6).

The result for facade permeability (figure 7) is more scattered that would be anticipated. For example, the Villa Savoye, Villa Cook and Villa Stein and De Monzie all feature elevations which are more complex than can be explained by their number of openings alone. However, a close review of these façades reveals that Le Corbusier's predilection for balconies, external stairs and roof gardens adds formal complexity that is, as far as the parameters of the present paper are concerned, functional rather than ornamental. 


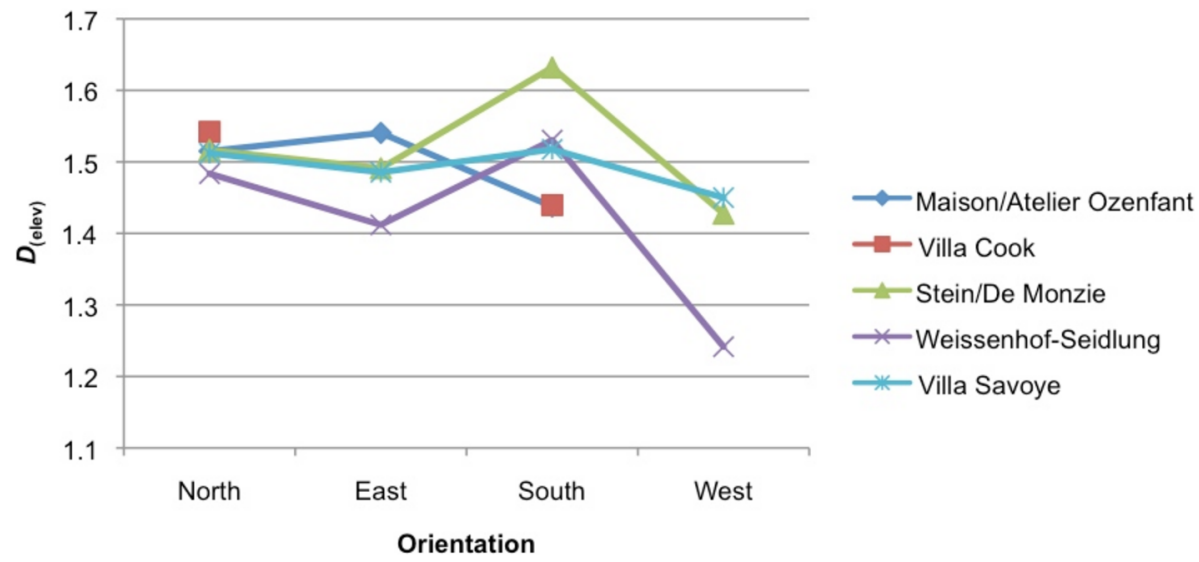

Figure 5: Correlation of Façade Complexity and Orientation Results for Le Corbusier

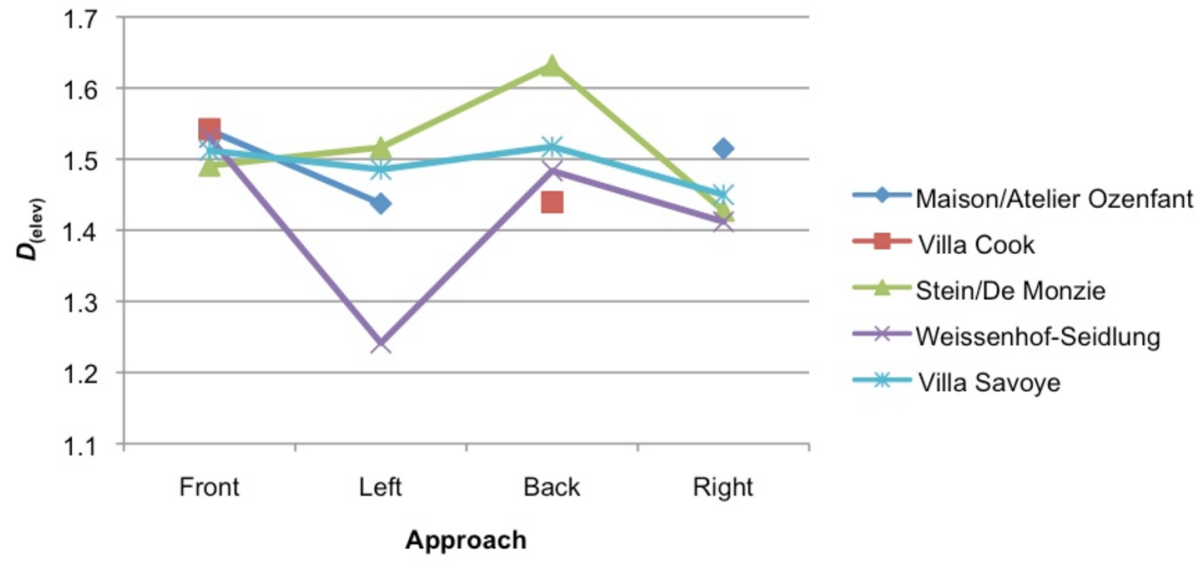

Figure 6: Correlation of Façade Complexity and Approach Results for Le Corbusier 


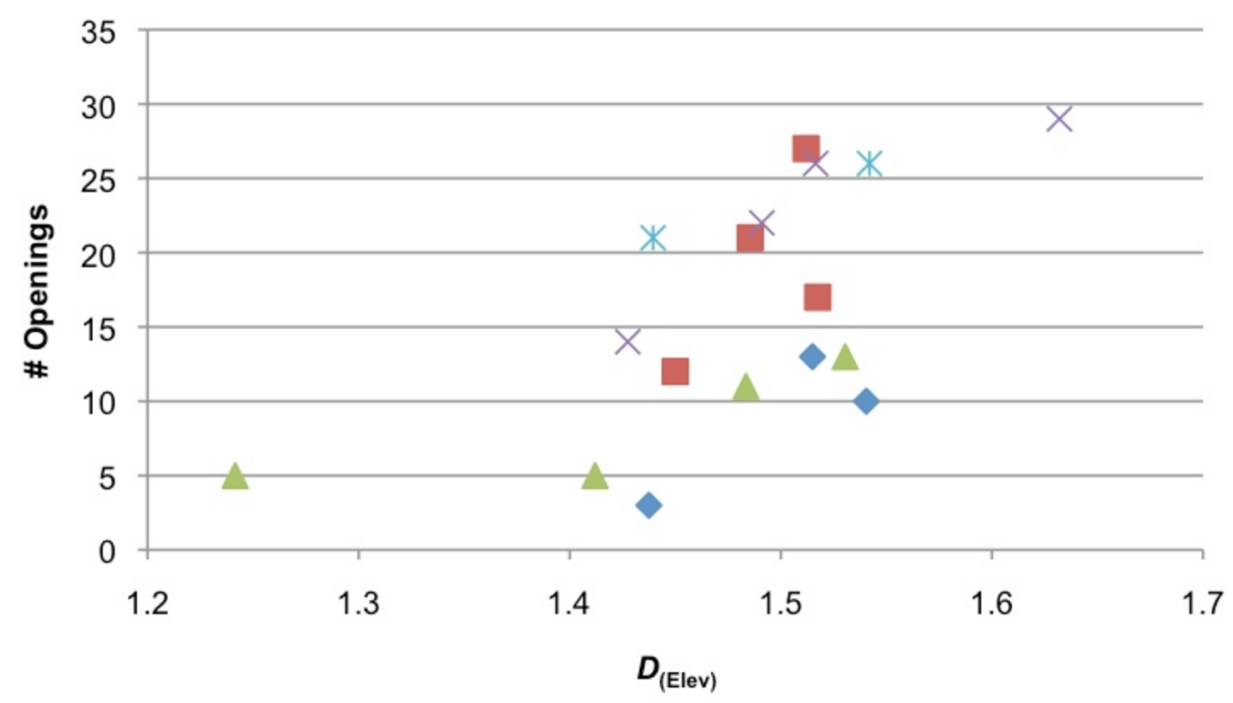

Figure 7: Correlation of Façade Complexity and Permeability Results for Le Corbusier

Key: Maison/Atelier Ozenfant, * Villa Cook, $\times$ Stein/De Monzie, $\boldsymbol{\Delta}$ Weissenhof-Seidlung, - Villa Savoye

\section{Gray: Results and Discussion}

The five houses by Eileen Gray were designed between 1926 and 1934 for sites in Southern France. Only two of the houses were completed although the unbuilt projects were documented in sufficient detail that they can be analysed. The first of these five designs, the unbuilt Small House for an Engineer (1926), is a split-level house and office design with a large ground floor that opens out into its gardens. Hecker observes of this house that the "upper floor [...] reveals itself astonishingly as an interpretation of Le Corbusier's five points for modern architecture" (1993:42). Gray's first built work, E.1027 (1929), is located in Roquebrune on the Côte d'Azur, France. This two storey house set in a steep hillside, is Gray's best known work and, according to Constant and Wang, "[w]ith this house Gray proved her abilities internationally. At that time", they propose, "no other architect had produced anything comparable" (1996:unpag.). Featuring elongated, white concrete walls and overhangs, with steel balustrades and strip windows, Gray acknowledges the "maritime character of the house" and the influence of the nearby sea (Hecker 1993:60). The Four Storey House (c. mid 1930's), an unbuilt project, is Gray's largest building design and it has strong similarities to E.1027. The house plan includes a gallery and bar in a large internal void and, on the roof terrace, a gym, sunbathing terrace, shower and dressing room. Gray's Tempe à Pailla (1934) in Castellar, is sited on a long, narrow, hillside block with distant views over the sea and mountains. Gray designed the house for her own residence, with rooms for her maid and chauffeur, as "a place of isolation and retreat" (Constant and Wang 1996:136). The fifth of Gray's designs, the House for Two Sculptors (1934), features a dynamic, curved two storey studio intersecting with a single storey rectilinear residence. The 
form of this design is described by Hecker as an "oval shape" that "is cut up into crescentshaped parts, which are then displaced vertically, one against the other. Placed on pillars, a cylinder-shaped [...] transparent volume is created" (1993:162).

Table 2: Results for Fractal Analysis of Each Façade for the Five Houses by Gray, Coded by Orientation, Approach and Permeability

\begin{tabular}{|c|c|c|c|c|}
\hline House & $D_{\text {(Elev) }}$ & Orientation & Approach & Permeability \\
\hline \multirow[t]{3}{*}{ House for an Engineer } & 1.347 & $\mathrm{~N}$ & $\mathrm{~F}$ & 4 \\
\hline & 1.292 & $\mathrm{E}$ & $\mathrm{L}$ & 4 \\
\hline & 1.231 & $\mathrm{~W}$ & $\mathrm{R}$ & 3 \\
\hline \multirow[t]{4}{*}{ E 1027} & 1.400 & $\mathrm{~N}$ & $\mathrm{~F}$ & 29 \\
\hline & 1.466 & $\mathrm{E}$ & $\mathrm{L}$ & 24 \\
\hline & 1.535 & $S$ & $\mathrm{~B}$ & 39 \\
\hline & 1.456 & $\mathrm{~W}$ & $\mathrm{R}$ & 9 \\
\hline \multirow[t]{4}{*}{ House for two Sculptors } & 1.432 & $\mathrm{~N}$ & B & 5 \\
\hline & 1.423 & $\mathrm{E}$ & $\mathrm{R}$ & 3 \\
\hline & 1.377 & $\mathrm{~S}$ & $\mathrm{~F}$ & 7 \\
\hline & 1.470 & $\mathrm{~W}$ & $\mathrm{~L}$ & 6 \\
\hline \multirow[t]{4}{*}{ Tempe a Pailla } & 1.290 & $\mathrm{~N}$ & $\mathrm{~F}$ & 4 \\
\hline & 1.401 & $\mathrm{E}$ & $\mathrm{R}$ & 18 \\
\hline & 1.429 & $\mathrm{~S}$ & B & 14 \\
\hline & 1.393 & $\mathrm{~W}$ & $\mathrm{~L}$ & 20 \\
\hline \multirow[t]{4}{*}{ Four Storey Villa } & 1.301 & $\mathrm{~N}$ & $\mathrm{~L}$ & 6 \\
\hline & 1.391 & $\mathrm{E}$ & B & 7 \\
\hline & 1.373 & S & $\mathrm{R}$ & 14 \\
\hline & 1.285 & $\mathrm{~W}$ & $\mathrm{~F}$ & 3 \\
\hline
\end{tabular}

The results of the computational fractal analysis of Gray's houses are contained in Table 2. In these results, the least visually complex façades were typically part of the House for an Engineer (ranging between $1.231<D_{\text {(Elev) }}<1.347$ ) and the most complex are for E1027 $\left(1.400<D_{\text {(Elev) }}<1.535\right)$. This means that the simplest elevation of E1027 is more fractal than the most complex elevation of the House for an Engineer. Another observation is that Gray's completed works all exhibit a higher degree of formal complexity that her unbuilt works, suggesting that as each design developed, she modified them to add elements (sunscreens, shutters, railings) in response to the growing practicalities of siting and construction. Of the unbuilt works, the House for Two Sculptors is amongst the most consistently complex in part because it has an oval volume in plan leading to a cylindrical form (see figure 8). When analysed through its representation in four elevations, some of the small details in the 
façade may be artificially counted twice increasing the fractal dimension. Despite this anomaly, the overall impact on the results is negligible.

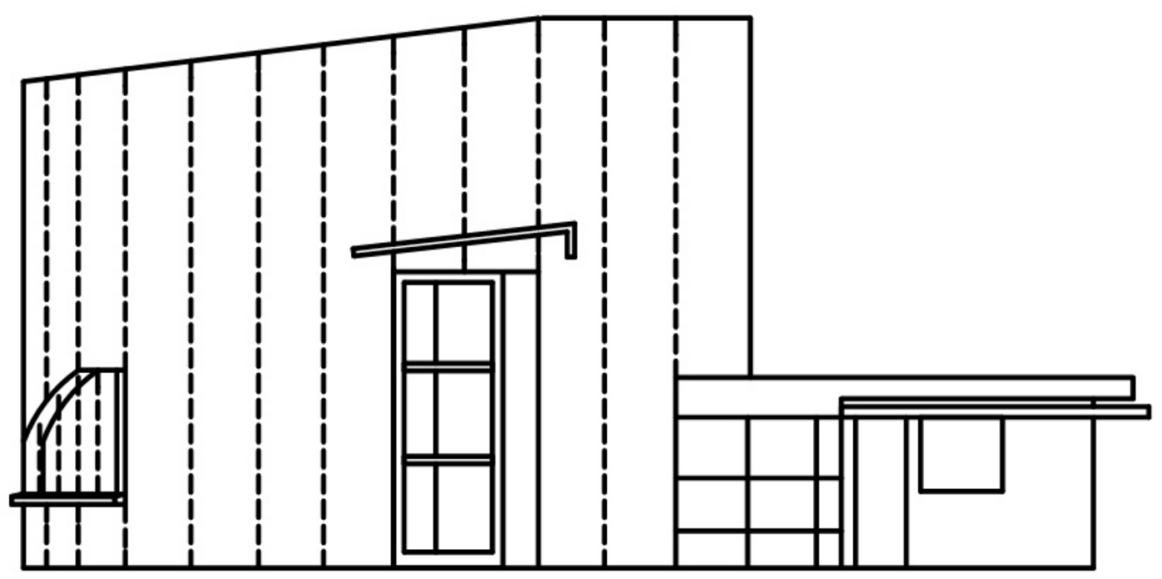

Figure 8: Eileen Gray's House for Two Sculptors. $\mathrm{D}_{(\mathrm{Elev})}=1.47$

In the orientation chart for Gray (figure 9) there is a partial pattern for three of the houses (E1027, Tempe a Pailla, Four Storey Villa) wherein the north and west elevations are relatively low in visual complexity while the east and south are slightly higher. These houses not only happen to be Gray's most developed designs, but they follow a similar pattern to Le Corbusier's houses on greenfield sites and to the example results outlined in the method section of the present paper.

The approach chart for Gray (figure 10) is primarilly of interest because it so closely resembles the orientation chart for her houses. With three of the five houses designed for rural sites, and two for idealised rural sites, Gray evidently adopted a clear design method wherein, in almost every case, the northern elevation was also the front and the southern the rear.

Much like Le Corbusier, whose work bears many similarities to Gray's, her permiability chart (figure 11) is slightly higher, or more "form rich", than might be anticipated from the impact of the openings alone. However, Grays elevations also feature extensive balconies, external stairs, sun hoods, and roof elements; all of which can broadly be considered functional devices. 


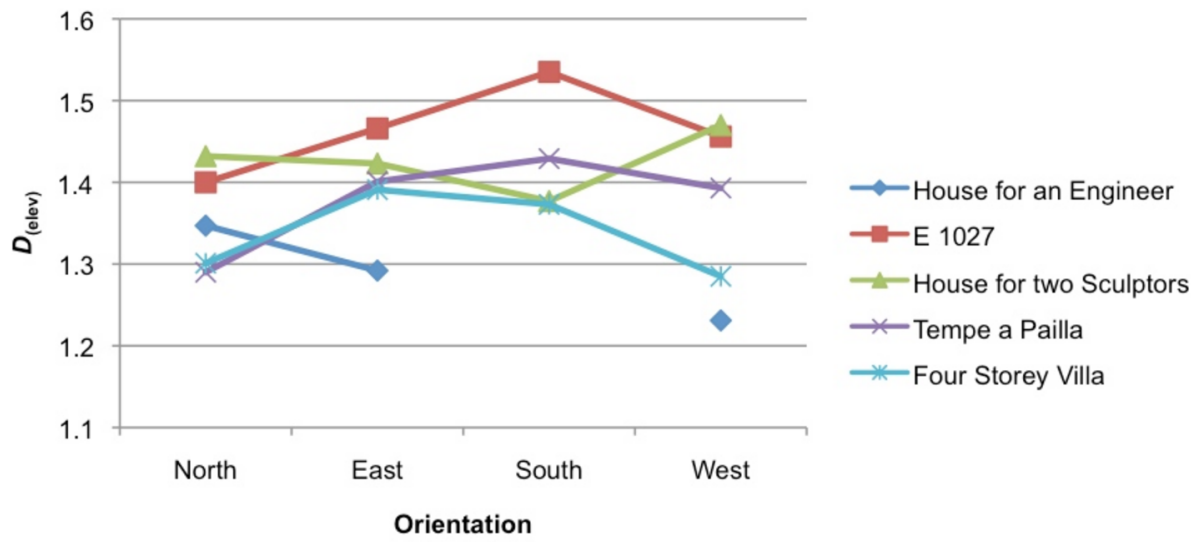

Figure 9: Correlation of Façade Complexity and Orientation Results for Gray

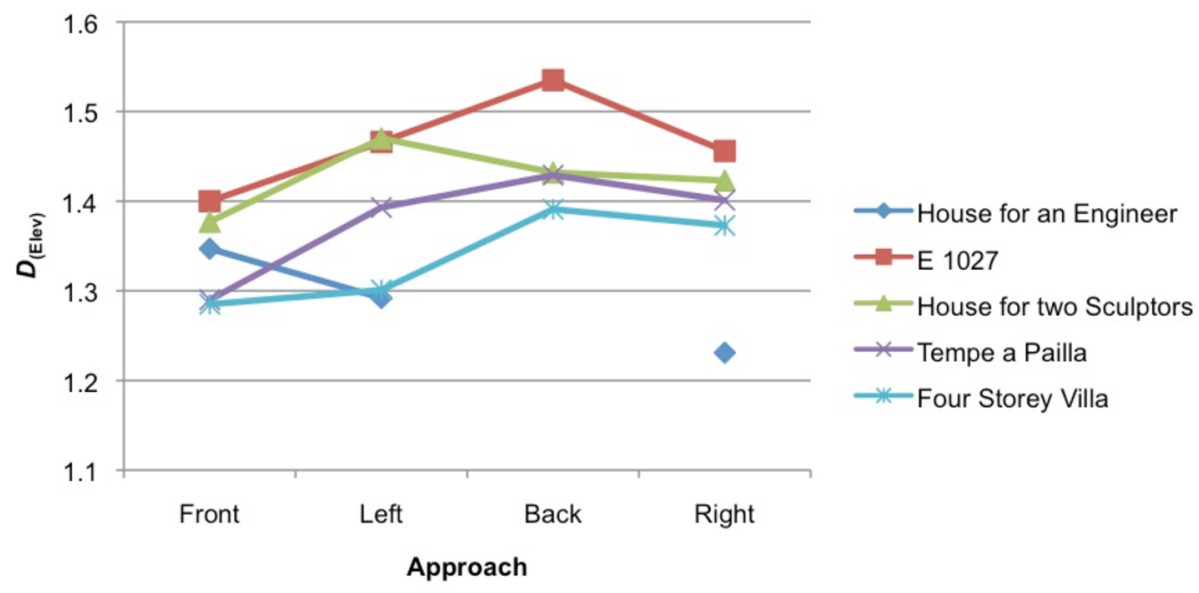

Figure 10: Correlation of Façade Complexity and Approach Results for Gray 


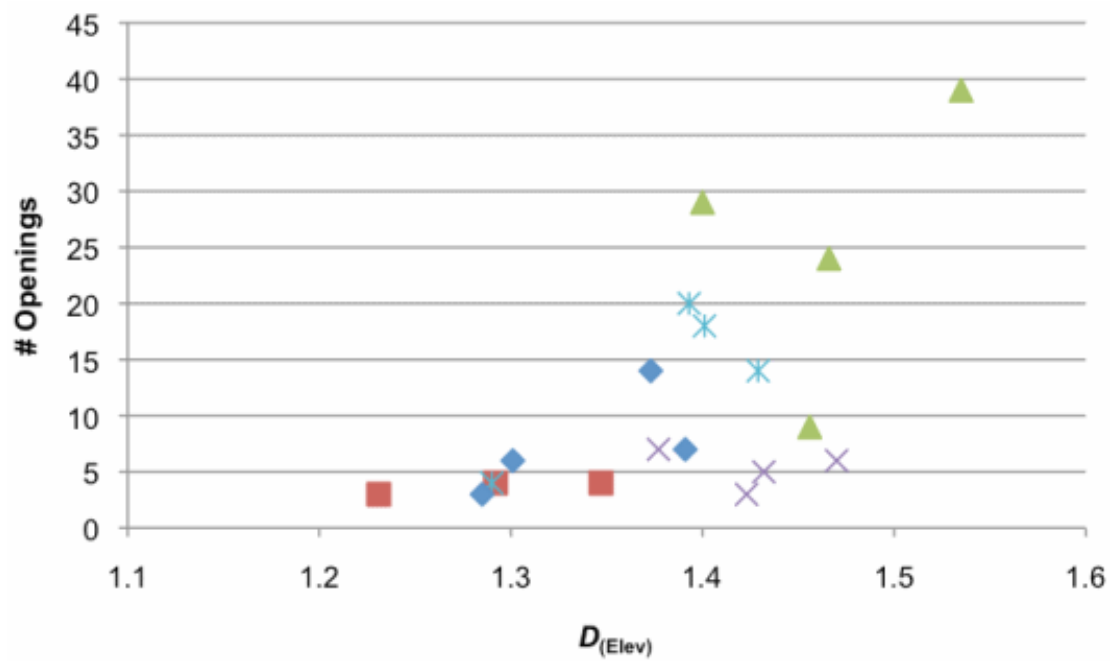

Figure 11: Correlation of façade complexity and permeability results for Gray

Key: - House for an Engineer, $\boldsymbol{\Delta}$ E1027, $\times$ House for two Sculptors, $*$ Temp a Pailla, Four Storey House

\section{Conclusion}

This paper utilises the computational method for fractal analysis as a means of testing the common view in architectural design, that form is shaped by a combination of environmental (orientation), phenomenological (approach) and functional (permeability) conditions. The purpose of the paper was not to test this proposition, but to use a limited set of data (36 elevations, augmented in 12 ways, to develop 432 results) to demonstrate a method that might be adapted for this purpose. The results of the present paper largely support the application of this method as a potentially useful approach for investigating the relationship between formal qualities and external forces. For example, for houses on green-field sites, the results seemed to provide evidence that orientation shaped the designs. More importantly, for these ten houses, the quantitative results broadly supported the anticipated qualitative results; that is, the data matched the conventional scholarly interpretation of how adaptive and responsive each of these works are.

Ultimately, the method proposed in the present paper can never adequately accommodate the full complexity of a work of architecture. Buildings are necessarily contingent objects; they are shaped by a multitude of forces and each project is different, even if the architect has a strong vision or strategy that transcends individual projects. Houses also possess symbolic and semiotic qualities that cannot be easily investigated using the present method. For all of these reasons, the method proposed in the present paper is unlikely to be widely applicable, but it can, as demonstrated here, uncover quantitative evidence for some previously poorly understood relationships between form, context and function. 


\section{Acknowledgements}

This research was supported by an Australian Research Council, Discovery Project grant (ARCDP): DP0770106.

\section{References}

Bechhoefer, W., Appleby, M. (1997) "Fractals, Music and Vernacular Architecture.” In Critical Methodologies in the Study of Traditional Environments. University of California at Berkeley: Berkeley.

Bovill, C. (1996) Fractal Geometry in Architecture and Design. Birkhäuser: Boston.

Bovill, C. (1997) "Fractal Calculations in Vernacular Design." In Critical Methodologies in the Study of Traditional Environments. University of California at Berkeley: Berkeley.

Box, H. (2007) Think Like an Architect. University of Texas Press: Austin.

Burkle-Elizondo, G., Sala, N., Valdez-Cepeda, R. D. (2004) "Geometric and Complex Analyses of Maya Architecture.” In Nexus V. K. Williams and F. Delgado Cepeda, eds. K. Williams Books: Florence.

Ching, F. D. (2007) Architecture: Form, Space, and Order. Wiley: London.

Constant, C. and Wang, W. (1996) Eileen Gray: An Architecture for All Senses. Ernst J. Wasmuth: Tübingen.

Feininger, A. (1956) The Anatomy of Nature: How Function Shakes the Form and Design of Animate and Inanimate Structures Throughout the Universe. Thomas Yoseloff: Berlin.

Foroutan-Pour, K. Dutilleul, P. and Smith, D. L. (1999) "Advances in the implementation of the boxcounting method of fractal dimension estimation," Applied Mathematics and Computation. 105 (2): 195-210.

Frederick, M. (2007) 101 Things I Learned in Architecture School. The MIT Press: Cambridge Mass.

Gans, D. (2000) The Le Corbusier Guide. Princeton: Princeton Architectural Press.

Grillo, P. J. (1975) Form, Function and Design. Dover Publications: London.

Hecker, Stefan. (1993) Eileen Gray, Works and Projects. Gustavo Gili: Barcelona.

Jones, J. C. (1992) Design Methods: Architecture. Wiley: New York.

King, P. (2005) The Common Place: The Ordinary Experience of Housing. Ashgate: London.

Kruft, H. W. (1994) A History of Architectural Theory from Vitruvius to the Present. Princeton: New York.

Leatherbarrow, D. (2000) Uncommon ground. Cambridge, Mass.; MIT Press.

Li, J., Du, Q., and Sun, C. (2009) "An improved box-counting method for image fractal dimension estimation." Pattern Recognition, 42 (11), 2460-2469.

Lorenz, W. (2003) "Fractals and Fractal Architecture. Masters Diss." Vienna University of Technology: Vienna.

Makhzoumi, J., Pungetti, G. (1999) Ecological Landscape Design and Planning. E \& FN Spon: London.

Mandelbrot, B. (1982) The Fractal Geometry of Nature. WH Freeman and Company: San Francisco.

Moore, C., Allen G. and Lyndon D. (1974) The place of houses. Holt, Rinehart and Winston: New York

Ostwald, M. J., and Vaughan, J. (2008) "Determining the Fractal Dimension of the Architecture of Eileen Gray," in ANZASCA 08: Innovation Inspiration and Instruction. ANZSACA: Newcastle, 9-16.

Ostwald, M. J., and Vaughan, J. (2009) "Calculating visual complexity in Peter Eisenman's architecture: A computational fractal analysis of five houses (1968-1976)." In CAADRIA 2009. CAADIA: Taiwan, 75-84.

Ostwald, M. J., Vaughan, J. and Chalup, S. K. (2009) "A Computational Investigation into the Fractal Dimensions of the Architecture of Kazuyo Sejima”, Design Principles and Practices, 3 (1), $231-244$. 
Vaughan, J. and Ostwald, M. J. (2009) "A computational comparison between the pre-modern (19051912) and early modern (1922-1928) architecture of Le Corbusier." Design Principles and Practices, 3 (9) 359 - 371.

Venturi, R. (1966) Complexity and Contradiction in Architecture. The Museum of Modern Art: New York.

\section{About the Authors}

\section{Prof. Michael J. Ostwald}

Professor Michael J. Ostwald is Dean of Architecture at the University of Newcastle, Australia, a Visiting Professor at RMIT University (Melbourne) and a Professorial Research Fellow at Victoria University Wellington.He has a PhD in architectural history and theory and a higher doctorate (DSc) in the mathematics of design. He has lectured in Asia, Europe and North America and has written and published extensively on the relationship between architecture, philosophy and geometry. Michael Ostwald is a member of the editorial boards of the Nexus Network Journal and Architectural Theory Review and he is co-editor of the journal Architectural Design Research.

\section{Josephine Vaughan}

Josephine Vaughan is a research higher degree candidate at the University of Newcastle, where she is also a member of the architectural computing research group. Her postgraduate studies are focused on the fractal dimensions of buildings. Josephine's architectural designs have been exhibited and installed regionally and nationally. 